\title{
Discrimination of the Socio-Economic Impact of the Corona Virus Disease Pandemic in Kinshasa, in the Democratic Republic of the Congo: A Population-Based Cross-Sectional Survey
}

\author{
Aliocha Nkodila Natuhoyila ${ }^{1,2,3}{ }^{*}$, Charles Mbendi Nlombi², Hervé Alex Tukadila Kabangi1, \\ Gilbert Mananga Lelo ${ }^{4}$, Philippe Lukanu Ngwala ${ }^{3}$, Benjamin Longo Mbenza ${ }^{1,2}$ \\ ${ }^{1}$ Faculty of Public Health, LOMO University Reseach, Kinshasa, Democratic Republic of the Congo \\ ${ }^{2}$ Department of Internal Medicine, University of Kinshasa, Kinshasa, Democratic Republic of the Congo \\ ${ }^{3}$ Faculty of Family Medicine, Protestant University in Congo, Kinshasa, Democratic Republic of the Congo \\ ${ }^{4}$ Neuropsychopathological Center, University of Kinshasa, Kinshasa, Democratic Republic of the Congo \\ Email: ^nkodilaaliocha@gmail.com
}

How to cite this paper: Natuhoyila, A.N., Nlombi, C.M., Kabangi, H.A.T., Lelo, G.M., Ngwala, P.L. and Mbenza, B.L. (2021) Discrimination of the Socio-Economic Impact of the Corona Virus Disease Pandemic in Kinshasa, in the Democratic Republic of the Congo: A Population-Based Cross-Sectional Survey. Open Access Library Journal, 8: e7302.

https://doi.org/10.4236/oalib.1107302

Received: March 11, 2021

Accepted: April 10, 2021

Published: April 13, 2021

Copyright $\odot 2021$ by author(s) and Open Access Library Inc.

This work is licensed under the Creative Commons Attribution International License (CC BY 4.0).

http://creativecommons.org/licenses/by/4.0/ (c) (i) Open Access

\begin{abstract}
Background and Aim: It has been ten months since the first case of COVID-19 was reported in Democratic Republic of Congo. Since then, the households have been on finding a cure for the disease. Largely neglected is the socioeconomic impact of the pandemic on the population in the country. The aim of the study is to measure the impact of the COVID-19 pandemic on the living conditions of households in Kinshasa. Methods: The design of this study is a cross-sectional study. A standard questionnaire was used to collect the data. The Revised Event Impact Scale (IES-R) was used to assess the socioeconomic impact of households. Factors with significant impact were sought by wald's discriminant and logistic regression analysis. Results: About four in five respondents had a significantly psychological impact (ISE-R score $>1$ ). Serious socio-economic impact was significantly associated with women, a liberal profession, a low level of education, and attending revival churches. On the other hand, the use of a mask, regular hand washing, knowledge of the consequences of containment and knowledge of the mode of transmission of COVID-19 reduced the risk of significant impact. Conclusion: Approximately $85 \%$ households surveyed had a significantly socioeconmic impact due to the pandemic which highlights the need for more longitudinal studies to be conducted on this age group. Urgent care and appropriate formulation of policies are needed to address the identified problems and to
\end{abstract}


provide care to those in need.

\section{Subject Areas}

Socioeconomics

\section{Keywords}

COVID-19 Pandemic, Socioeconmic Impact, Households, Kinshasa

\section{Introduction}

When the health crisis linked to the coronavirus became pandemic affecting countries around the world at an incredible progression, the Congolese state immediately took measures to manage this crisis [1] [2]. These include the suspension of its air links to the rest of the world, the closure of schools and the proclamation of a state of health emergency by the President of the Democratic Republic of Congo (DRC) on Tuesday 24 March 2020 following the recording of the progression of cases since the appearance of the first on March 10, 2020 [3] [4]. From there, every two weeks, the national response plan against COVID-19 is revised to comply with the emergency situation [5].

With data reported up to Wednesday, March 13, 2021. The DRC records 21 new cases of coronavirus contamination (data from INRB laboratories and validated by the DRC's COVID-19 Multisectoral Response Committee). The total number of positive cases for the novel coronavirus in the Democratic Republic of the Congo is 26,759 ( 26,758 confirmed cases and 1 probable case). The total of fatal cases in the DRC as of March 13, 2021 is 712 (711 confirmed fatalities and one probable case). Lethality is $2.6 \%$. The total number of people cured of the coronavirus, COVID-19 in the DRC is 22,432 . Cure rate is $84 \%$. Total active cases are 3615. The circulation of the SARS-CoV-2 virus continues in the DRC with still new infections every day in the active provinces. It is in this context that the Ministry of Health announced the start of the vaccination campaign against the coronavirus, COVID-19 piloted by the Expanded Program of Vaccination (EPI) from the coming days.

The DRC trades directly with countries in Europe and Asia, it suffers from the economic consequences of the COVID-19 pandemic at the international level due to the substantial severing of its trade links with the countries severely affected by Asia and Europe. At the national level, the application of restrictive measures has upset the daily lives of households both socially and economically following the confinement of the commune of Gombe, a place hosting several companies in the country [6] [7]. In fact, the peculiarity of this crisis means that it puts double pressure on both supply and national demand [8]. The purpose of the study is indeed to measure the impact of the COVID-19 pandemic on the living conditions of households in Kinshasa. 


\section{Methods}

An analytical cross-sectional study was conducted in the city of Kinshasa province during the period from June to October 2020.

The study population consisted of the inhabitants of the city province of Kinshasa, more specifically the heads of households or their respondents. Simple probability and random sampling with a sample step of 3 was used to collect data for these studies. The sample size was calculated from Fisher's formula: $\mathrm{n} \geq$ $\left(\mathrm{Z}^{2} \times(\mathrm{p})(1-\mathrm{p})\right) / \mathrm{d}^{2}$ where $\mathrm{n}=$ Sample size, $\mathrm{z}=1,96$ (confidence coefficient), $\mathrm{p}=$ previous prevalence, $\mathrm{d}=0.05$ (margin of error or range of imprecision reflecting the degree of absolute precision desired). Because of the probable non-responding subjects, $10 \%$ of the number calculated at the height should be added. We estimated that the negative impact of the COVID-19 pandemic has reached $50 \%$ of households, as prescribed in the literature, in the absence of a prevalence of such a documented consequence in the country. The sample size thus calculated was $\mathrm{n} \geq(1.96) 2 \times 0.5 \times 0.5 /(0.05) 2=384$. By including the $10 \%$ of non-respondents, we obtained 422 heads of household to question. The sample was increased to 1510 finally to increase the statistical power of the test. Given the absence of the population register, the sampling was adapted to the administrative organization of the city of Kinshasa, which is subdivided into 24 communes, neighborhoods and streets. The study focused on 1510 subjects recruited at random according to a sampling plan with several stages with sampling units constituted at the 1st stage of the municipality, at the 2nd stage of the neighborhood, at the $3 \mathrm{rd}$ stage of the street, at the 4 th stage of the inhabited plot and at the 5th degree of the household.

The following variables were collected: the socio-demographic and economic characteristics of the respondents among which the following variables of interest were collected: sex, age, marital status, religion, level of education, family composition, socioeconomic level of households and the occurrence of an event during the pandemic (loss of employment, lack of food, forcing to stay at home, inability to access health care).

The data were collected by face-to-face interviews with heads of household or their spouses, using a pre-tested questionnaire. The face-to-face interview made it possible to reach all social layers knowing that the poorest do not have phones to reach them. Data collection was done on tablets.

The impact of the pandemic on the household of the population studied was measured using a score constructed from five questions on the occurrence of an event (loss of employment, insufficient food, drop in income in the household, forced to stay at home, inability to access health care). Each question consisted of two assertions (yes $=1$ and no $=0$ ). The score has a minimum of 0 and a maximum of 5. A less impact focus was defined when the score was between 0 1; medium impact, score between 2 - 3 and high impact, score between 4 - 5 [9].

\section{Statistical Analyzes}

The data collected was then transferred to SPSS for Windows version 21 for 
processing and analysis. Categorical variables were presented as absolute and relative frequency, quantitative variables were summarized by measures of central tendency and dispersion. The mean and its standard deviation were reported for variables with a normal distribution. Comparison of proportions was done using Pearson's Chi-square or Fischer's exact test. Student's t test made it possible to compare the means. Pearson's correlation established the correlation between socioeconomic impact and the implementation of government measures. The overall score and each of the socioeconomic events were tested for internal consistency using Cronbach's alpha $(\alpha)$. The factors implicated in the impact of the revised socio-economic events on the household (IESE-R) were sought by discriminant analysis. The search for factors associated with the socio-economic impact was done using the logistic regression test in multivariate analysis. The calculated adjusted ORs were used to estimate the degree of association between the socio-economic impact and the independent variables. The $\mathrm{p}$ value $<0.05$ was the threshold of statistical significance.

\section{Ethical Considerations}

The protocol for this research study was submitted and approved by the ethics committee of the Protestant University in Congo under Approval No. CEUPC0037. Prior to the administration of the questionnaire, each interviewer sought informed consent from the person to be investigated after a brief explanation of the study objectives. All selected subjects were told that participation in the study was voluntary, that they could stop the interview at any time, and that they were not required to answer all questions. The confidentiality of the respondent was guaranteed because no personal information that could link the respondent to their data was collected. There was no direct benefit from participating in the study but the results of the study will allow the government of the DRC to put in place interventions based on scientific evidence to cut the chain of transmission of the epidemic.

\section{Results}

\subsection{Sociodemographic Characteristics}

The interviewed population consisted of 802 men (53.1\%) and 708 women (46.9\%) sex ratio $1 \mathrm{H} / 1 \mathrm{~F}$. The mean age of the respondents was $40.3 \pm 16.8$ years with a significantly higher mean in men $(\mathrm{p}=0.002)$. Students were more numerous (35.9\%), they were also more married (39.6\%) of university level (44.8\%) of Kimbanguist religion, living in families of less than 6 people; with a socio-economic lower in the majority of cases (65.8\%). Compared to men and women, we found a statistically significant difference for occupation, marital status, level of education and religion $(\mathrm{p}<0.05)($ Table 1$)$.

\subsection{Knowledge and Application of the Measures Decreed by the Government}

The measures decreed by the government are illustrated in Table 2 and shows 
Table 1. Sociodemographic characteristics by sex.

\begin{tabular}{|c|c|c|c|c|}
\hline Variable & $\begin{array}{c}\text { Over all } \\
(\mathrm{n}=1510)\end{array}$ & $\begin{array}{c}\text { Male } \\
(\mathrm{n}=802)\end{array}$ & $\begin{array}{c}\text { Female } \\
(\mathrm{n}=708)\end{array}$ & $\mathrm{p}$ \\
\hline Age, Mean \pm SD, years & $40.3 \pm 16.8$ & $41.6 \pm 16.3$ & $38.9 \pm 17.3$ & 0.002 \\
\hline Profession & & & & $<0.001$ \\
\hline Official & $460(30.5)$ & $174(21.7)$ & $286(40.4)$ & \\
\hline Student & $542(35.9)$ & $380(47.4)$ & $162(22.9)$ & \\
\hline Liberal & $374(24.8)$ & $188(23.4)$ & $186(26.3)$ & \\
\hline Health person & $134(8.9)$ & $60(7.5)$ & $74(10.5)$ & \\
\hline Marital status & & & & $<0.001$ \\
\hline Single & $754(49.9)$ & $430(53.6)$ & $324(45.8)$ & \\
\hline Married & $598(39.6)$ & $348(43.4)$ & $250(35.3)$ & \\
\hline Windows & $146(9.7)$ & $24(3.0)$ & $122(17.2)$ & \\
\hline Divorced & $12(0.8)$ & $0(0.0)$ & $12(1.7)$ & \\
\hline Education level & & & & $<0.001$ \\
\hline No & $50(3.3)$ & $0(0.0)$ & $50(7.1)$ & \\
\hline Primary & $214(14.2)$ & $128(16.0)$ & $86(12.1)$ & \\
\hline Secondary & $570(37.7)$ & $184(22.9)$ & $386(54.5)$ & \\
\hline University & $676(44.8)$ & $490(61.1)$ & $186(26.3)$ & \\
\hline Religion & & & & $<0.001$ \\
\hline Catholic & $338(22.4)$ & $264(32.9)$ & $74(10.5)$ & \\
\hline Protestant & $290(19.2)$ & $176(21.9)$ & $114(16.1)$ & \\
\hline Revival Church & $386(25.6)$ & $128(16.0)$ & $258(36.4)$ & \\
\hline Kimbanguist & $496(32.8)$ & $234(29.2)$ & $262(37.0)$ & \\
\hline \multirow[t]{2}{*}{ Family composition } & $3.94 \pm 1.94$ & $3.95 \pm 1.91$ & $3.92 \pm 1.97$ & 0.71 \\
\hline & & & & 0.441 \\
\hline$<6$ people & $1166(77.2)$ & $621(77.4)$ & $545(77.0)$ & \\
\hline$\geq 6$ people & $344(22.8)$ & $181(22.6)$ & $163(23.0)$ & \\
\hline Socioeconomic level & & & & 0.315 \\
\hline Low & $994(65.8)$ & $532(66.3)$ & $462(65.3)$ & \\
\hline Midle & $306(20.3)$ & $152(19.0)$ & $154(21.8)$ & \\
\hline High & $210(13.9)$ & $118(14.7)$ & $92(13.0)$ & \\
\hline
\end{tabular}

that $39.7 \%$ of respondents adopted barrier gestures, $21.5 \%$ applied plus the hydroalcoholic solution, $17.5 \%$ no longer used the mask, $50.6 \%$ washed regularly hands. Regarding knowledge of symptoms, $33.3 \%$ had at least good knowledge; $31.5 \%$ were very informed about the consequences of confinement and $33.4 \%$ knew about the mode of contamination of COVID-19 (Table 2).

\subsection{Different Socio-Economic Events of the Outbreaks during the Pandemic}

The most common socio-economic consequences were low household income 
Table 2. Knowledge and application of the measures decreed by the government.

\begin{tabular}{|c|c|c|}
\hline Variables & $\mathrm{n}=1510$ & $\%$ \\
\hline \multicolumn{3}{|l|}{ Barrier gesture adoption } \\
\hline Some times & 40 & 2.6 \\
\hline Medlly & 870 & 57.6 \\
\hline Very adopted & 600 & 39.7 \\
\hline \multicolumn{3}{|c|}{ Application of hydroalcoholic solution } \\
\hline Not applied & 24 & 1.6 \\
\hline Some times & 126 & 8.3 \\
\hline Applied & 1036 & 68.6 \\
\hline Very applied & 324 & 21.5 \\
\hline \multicolumn{3}{|l|}{ Mask usage } \\
\hline Not applied & 12 & 0.8 \\
\hline Some times & 224 & 14.8 \\
\hline Applied & 1010 & 66.9 \\
\hline Very applied & 264 & 17.5 \\
\hline \multicolumn{3}{|l|}{ Regular hand washing } \\
\hline Not at all & 198 & 13.1 \\
\hline Sometimes & 548 & 36.3 \\
\hline Very often & 636 & 42.1 \\
\hline Always & 128 & 8.5 \\
\hline \multicolumn{3}{|l|}{ Knowledge of the disease symptom } \\
\hline Not at all & 388 & 25.7 \\
\hline Some knowledge & 618 & 40.9 \\
\hline Good knowledge & 464 & 30.7 \\
\hline Very good knowledge & 40 & 2.6 \\
\hline \multicolumn{3}{|c|}{ Knowledge of the consequences of confinement } \\
\hline Not at all & 422 & 27.9 \\
\hline I am little informed & 612 & 40.5 \\
\hline I am informed & 476 & 31.5 \\
\hline \multicolumn{3}{|c|}{ Knowledge of the contamination mode } \\
\hline Not at all & 658 & 43.6 \\
\hline A little knowledge & 348 & 23.0 \\
\hline Good knowledge & 490 & 32.5 \\
\hline Very good knowledge & 14 & 0.9 \\
\hline
\end{tabular}

(73.2\%), having to stay at home (69.1\%), food insufficiency (67.8\%), loss of employment (64.8\%) and inability to access health services (46.2\%) (Figure 1).

\subsection{Correlation between the Score of the Impact of Socio-Economic Events-Revised and the Application of Measures Decreed by the Government}

A positive and significant correlation was found between the impact of socio-economic-revised events, regular hand washing $(r=0.63, \mathrm{p}<0.001)$, knowledge 


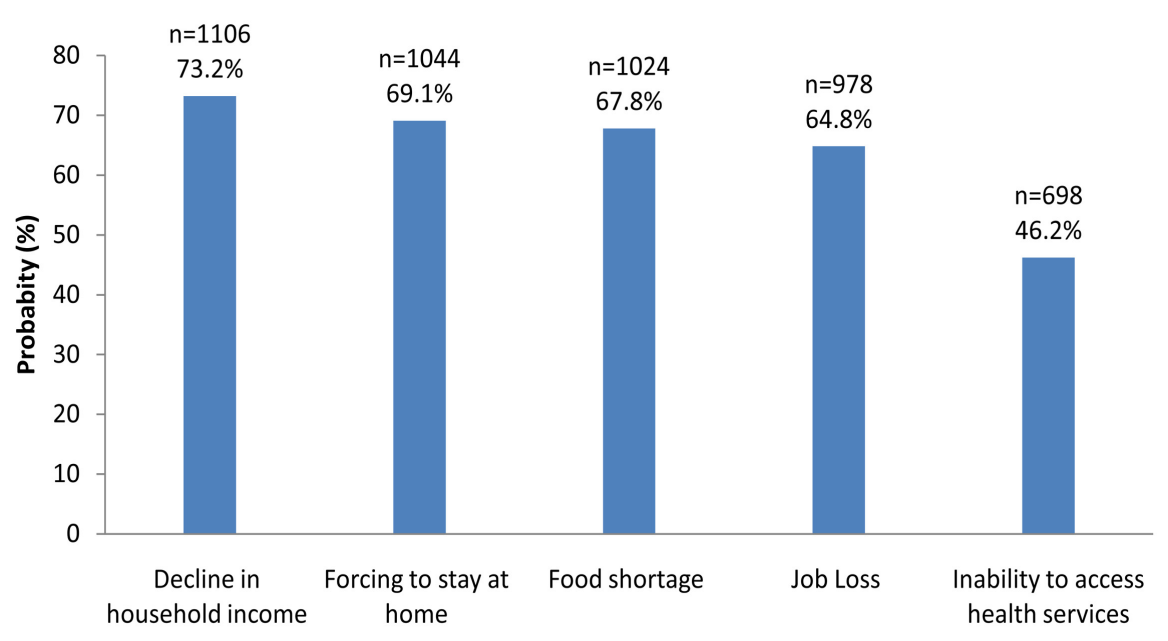

Figure 1. Different socio-economic events of the outbreaks during the pandemic.

about symptoms ( $\mathrm{r}=0.55, \mathrm{p}<0.001)$, knowledge of the consequences of confinement $(\mathrm{r}=0.57, \mathrm{p}<0.001)$ and knowledge of the mode of transmission of COVID-19 $(r=0.77, p<0.001)$. On the other hand, a negative and significant correlation was found between the impact of socio-economic events-revised the adoption of barrier gesture $(\mathrm{r}=0.64, \mathrm{p}<0.001)$ and the application of hydroalcoholic solutions $(\mathrm{r}=0.66, \mathrm{p}<0.001)$ (Table 3$)$.

\subsection{Impact of Socio-Economic Events on Households}

The IESE-R has been consistently used in several studies and is considered a good measure of the socio-economic impact of an event. The scale revealed a mean score of $3.2(\mathrm{SD}=1.5)$ with a median of 3 . Testing the overall reliability of the revised Socio-Economic Event Impact Scale revealed good internal consistency. $(\alpha=0.764)$.

Each participant was grouped into a separate category based on their IESE-R score. The pandemic had a significant impact on the outbreak of 1272 participants (84.5\%). As shown in Figure 2, 674 outbreaks (44.6\%) had a severe socio-economic impact due to the pandemic (Figure 2).

\subsection{Predictors of the Impact of Socio-Economic Events in Households}

In Table 4, 72.3\% of the variables are correlated with $58.8 \%$ of the socio-economic impact of households $(\mathrm{R} 2=0.588)$.

\subsection{Coefficients of Classification Functions}

The combined intra-group correlations between discriminant variables and the variables of the standardized canonical discriminant functions are ordered by absolute sizes of the correlations within the function. Variables with a larger absolute correlation size in function 3 were discriminated against as factors in the socio-economic impact of COVID-19 on households (Table 5). 
Table 3. Correlation between the score of the impact of SEE-R and the application of measures.

\begin{tabular}{lccc}
\hline \multicolumn{1}{c}{ Variable } & $\beta$ & $\mathrm{r}$ & $\mathrm{p}$ \\
\hline Barrier gesture adoption & -0.275 & 0.64 & $<0.001$ \\
Application of hydroalcoholic solution & -0.252 & -0.66 & $<0.001$ \\
Mask usage & 0.050 & 0.19 & 0.461 \\
Regular hand washing & 0.213 & 0.63 & $<0.001$ \\
Knowledge of the disease symptom & 0.296 & 0.55 & $<0.001$ \\
Knowledge of the consequences of confinement & 0.177 & 0.57 & 0.001 \\
Knowledge of the contamination mode & 0.240 & 0.77 & $<0.001$ \\
\hline
\end{tabular}

Table 4. Coefficients of the classification of the socio-economic impact function.

\begin{tabular}{ccccc}
\hline Function & Eigenvalue \% & \% of variance & \% cumulative & $\begin{array}{c}\text { Canonical } \\
\text { correlation }\end{array}$ \\
\hline 1 & 0.529 & 72.3 & 72.3 & 0.588 \\
2 & 0.203 & 27.7 & 100.0 & 0.411 \\
\hline
\end{tabular}

Table 5. Coefficients of classification functions.

\begin{tabular}{lccc}
\hline \multirow{2}{*}{\multicolumn{1}{c}{ Factors }} & \multicolumn{3}{c}{ Impact level } \\
\cline { 2 - 4 } & $\begin{array}{c}\text { Low } \\
\text { Impact }\end{array}$ & $\begin{array}{c}\text { Moderate } \\
\text { Impact }\end{array}$ & $\begin{array}{c}\text { High } \\
\text { Impact }\end{array}$ \\
\hline Sex & 8.155 & 9.273 & 9.180 \\
Mask usage & 9.164 & 8.729 & 8.086 \\
Educational level & 5.792 & 7.503 & 7.273 \\
Application of hydroalcoholic solution & 4.926 & 5.533 & 4.588 \\
Knowledge of the consequences of confinement & 3.010 & 1.974 & 2.620 \\
Profession & 2.673 & 1.237 & 1.799 \\
Knowledge of the disease symptom & -0.524 & 2.813 & 1.216 \\
Religion & 0.751 & 1.363 & 0.827 \\
Age & 0.141 & 0.203 & 0.206 \\
Knowledge of the contamination mode & -2.399 & -3.184 & -2.404 \\
Regular hand washing & -2.937 & -5.495 & -3.593 \\
(Intercept) & -42.094 & -46.040 & -44.455 \\
\hline
\end{tabular}

${ }^{*}$ Fisher linear discriminant functions.

\subsection{Canonical Discriminant Functions}

In the canonical function of variables, the abscissa represents the socio-demographic variables and the measures decreed by the government (independent variables) and the ordinate the socio-economic impact of COVID-19 on households (dependent variable). The figure, the factors associated (red color) with the severe impact are mostly located in the first quadrant, meaning when these values increase, there is a significant increase in the severe impact in the outbreaks (Figure 3). 

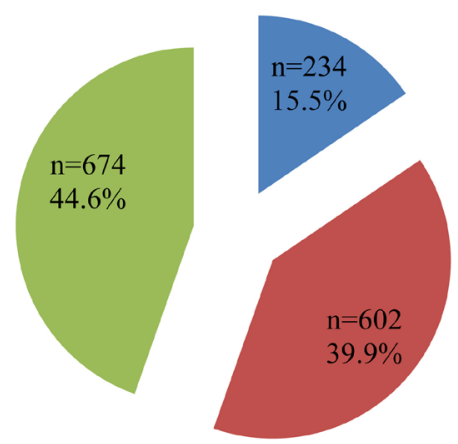

- Less impact

- Medium impact

- High impact

Figure 2. Level of socio-economic impact in households.

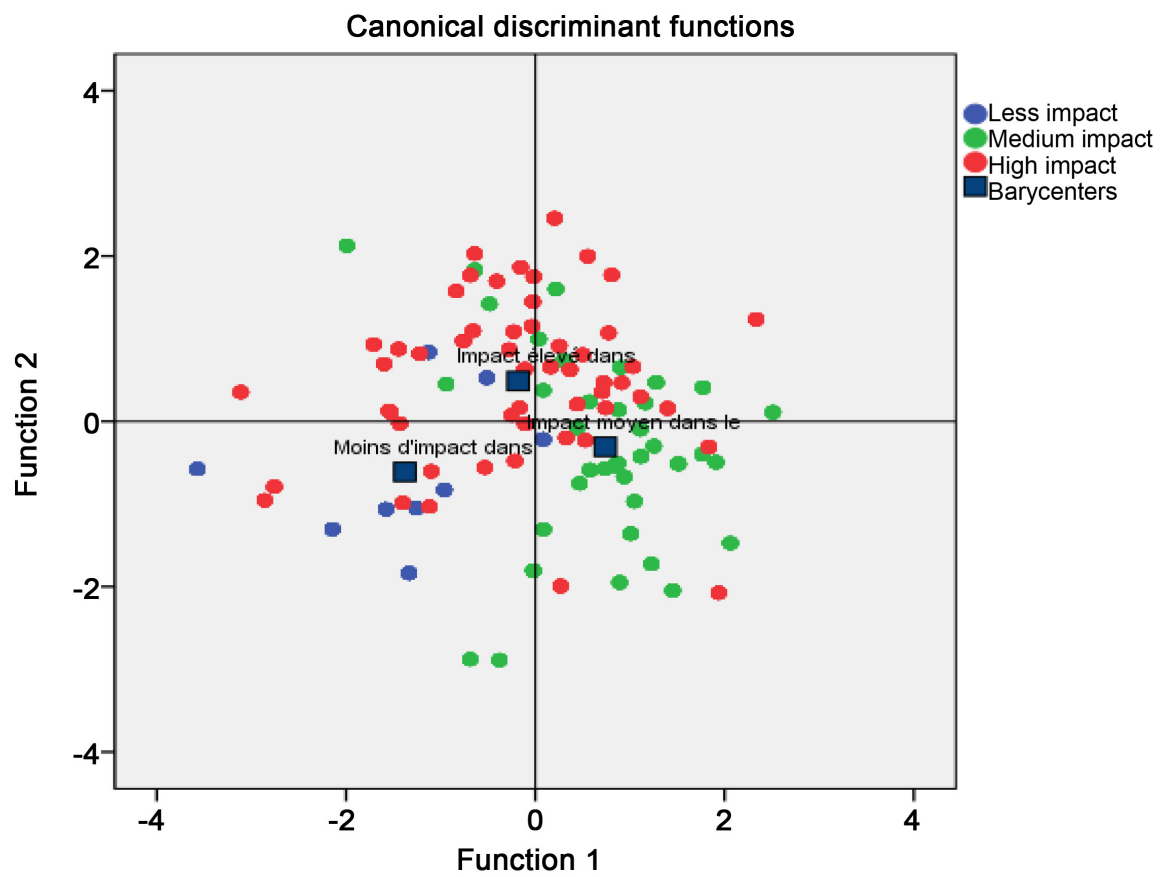

Figure 3. Canonical discriminant functions.

\subsection{Independent Factors Associated with Socio-Economic Impact}

Adjusting the factors that discriminate against the socio-economic impact of COVID-19 in the household showed that the household whose head of household exercised a liberal profession, had a low level of education and attended revival churches, had respectively 5, 7 and 3 times the risk of serious socio-economic impact. On the other hand, the use of a mask, regular hand washing, knowledge of the consequences of confinement and knowledge of the mode of transmission of COVID-19 reduced this risk by 10, 50, 5 and 3 times respectively (Table 6).

\section{Discussion}

The present study examined the impact of the COVID-19 pandemic on households in Kinshasa.

Among the 1510 respondents studied, the pandemic had a significant impact 
Table 6. Independent factors associated with socio-economic impact.

\begin{tabular}{|c|c|c|c|}
\hline Facteurs & $\beta$ & aOR $(95 \% \mathrm{CI})$ & $\mathrm{p}$ \\
\hline Sex (Male vs female) & 0.677 & $1.97(0.99-3.88)$ & 0.051 \\
\hline Profession (liberal vs others) & 2.975 & $5.10(2.90-8.90)$ & $<0.001$ \\
\hline Educational level (Low vs High) & 4.674 & $7.14(3.43-9.16)$ & $<0.001$ \\
\hline Religion (Revival Church vs traditional) & 0.955 & $2.60(1.94-3.47)$ & $<0.001$ \\
\hline $\begin{array}{l}\text { Application of hydroalcoholic solution } \\
\text { (No vs Yes) }\end{array}$ & 0.072 & $1.08(0.58-1.99)$ & 0.819 \\
\hline Mask usage (No vs yes) & -2.275 & $0.10(0.05-0.22)$ & $<0.001$ \\
\hline Regular hand washing (No vs yes) & -6.012 & $0.02(0.01-0.08)$ & $<0.001$ \\
\hline Knowledge of the disease symptom (No vs yes) & 9.246 & $10.36(2.38-14.47)$ & $<0.001$ \\
\hline $\begin{array}{l}\text { Knowledge of the consequences of } \\
\text { confinement (No vs yes) }\end{array}$ & -1.588 & $0.20(0.08-0.51)$ & 0.001 \\
\hline $\begin{array}{l}\text { Knowledge of the contamination mode } \\
\text { (No vs yes) }\end{array}$ & -0.924 & $0.39(0.21-0.74)$ & 0.004 \\
\hline Intercept & 2.672 & 14,476 & 0.068 \\
\hline
\end{tabular}

(moderate/severe) in 1272 participants (84.5\%). These results join other studies conducted in the same in other countries such as that of Varshney et al. in early March in India which showed that the pandemic had a significant impact on a third of participants [10]. Another study conducted in China reported that $53.8 \%$ of participants had a significant impact, while another reported that only $7.6 \%$ of participants had a significant impact [11] [12]. This significant socio-economic impact could be explained in our context of confinement of the commune of Gombe, a place hosting the majority of the country's commercial activities. The limitation of population movements by the government and the technical team of the response against COVID-19 with the slogan stay at home is one of the reasons for this harmful socio-economic consequence of the households in Kinshasa. Along the same lines as our study, Young Minds found that $83 \%$ of its respondents reported declining health care, disruption of household income, loss of employment, and school/university closures [13].

The socio-demographic variables discriminating the socio-economic impact show that women tended to have a significantly greater socio-economic impact than men. These results are similar to the results of several studies conducted in the general population in 2020 [10] [11] [14].

Respondents with a liberal profession and those with a low level of education were more likely to have a significantly severe socio-economic impact from the pandemic. This finding is similar to those noted by researchers in Bangladesh and Spain [15] [16]. This finding may be due to the fact that a greater income of people comes daily from odd jobs they do in the commune of Gombe which was at the time confined.

Respondents with knowledge of the consequences of confinement and the mode of transmission had significantly reduced their significant impact in their home. These results are similar to the results of Zhang \& Ma and Plomecka et al. 
[12] [17]. This is because knowledge increases vigilance and prudence in anticipating the effect that may occur in the future.

The increase in barrier gestures such as mask use and regular hand washing among respondents had also reduced the significant severe impact of outbreaks in this study. These measures allow the people who applied them to no longer fear contamination of the virus and to manage differently to prevent the consequences of households. For these people, applying these measures allowed them to go out without conforming to the slogan stay at home. So applying the barrier measures gave increased confidence and self-esteem and as a result many could no longer stay at home and believe that applying the barrier measures can be a simple strategy to build resilience to the pandemic [18].

Limitations of the study: certain limitations must be taken into account when analyzing the results. Collecting data from a population limited to a single city does not therefore make it possible to generalize the results in all the cities of the DRC. The study involved self-report measures where the respondent might not have any data about their situation, which could not establish the causal link. Despite the limitations, this study provides cross-sectional data on the economic impact of the pandemic in the Kinshasa focus. Further longitudinal studies should be conducted to confirm the results and formulate guidelines for the population of Kinshasa during the next pandemic.

\section{Conclusion}

The COVID-19 pandemic has raised several concerns for homes in the city of Kinshasa. This survey is one of the first to examine the socio-economic impact of the COVID-19 pandemic on households in Kinshasa. The study reported that the pandemic had a significant impact on the lives of households. Households with a liberal professional head of household, with a low level of education, attending revival churches and having knowledge of the symptom of COVID-19, tended to have a greater socio-economic impact. Certain measures such as the application of a barrier gesture, regular hand washing, knowledge of the consequences of containment and the mode of contamination significantly reduced the socio-economic impact of the outbreaks. The results of the study should be used by stakeholders to formulate policies and help households adapt in the event of a pandemic of another disease.

\section{Authors' Contributions}

ANN and CMN designed and analyzed the statistical data for the study. HATK contributed to the data collection. PLN, GLM and BLM supervised the study. All authors have read and approved the final and revised version of the manuscript.

\section{Acknowledgements}

The authors are thankful to all who participated in the study. 


\section{Conflict of Interest Disclosures}

The authors declare no conflicts of interest regarding the publication of this paper.

\section{References}

[1] Organisation mondiale de la santé (OMS) (2020) Nouveau Coronavirus-Chine.

[2] Huang, C., Wang, Y., Li, X., Ren, L., Zhao, J., Hu, Y., et al. (2020) Caractéristiques cliniques des patients infectés par le nouveau coronavirus 2019 à Wuhan, en Chine. The Lancet, 395, 497-506. https://doi.org/10.1145/2181037.2181040

[3] OMS (2020) Flambée de maladie à coronavirus (COVID-19) en RDC.

[4] Center for Systems Science and Engineering (CSSE) (2020) Tableau de bord COVID-19 par. ArcGIS. Université Johns Hopkins.

[5] Centres américains de contrôle et de prévention des maladies (CDC) (2020) Conseils cliniques provisoires pour la prise en charge des patients atteints d'une maladie confirmée à coronavirus (COVID-19).

[6] Organisation mondiale de la santé (OMS) (2020) Déclaration sur la deuxième réunion du Comité d'urgence du Règlement sanitaire international (2005) concernant l'apparition d'un nouveau coronavirus (2019-nCoV). 30 janvier 2020. Archivéde l'original le 31 janvier 2020.

[7] Hopkins, C. (2020) Perte de l'odorat comme marqueur de l'infection au COVID-19. Corps de chirurgie de l'oreille, du nez et de la gorge du Royaume-Uni.

[8] Organisation mondiale de la santé (2020) Allocution d'ouverture du Directeur général de l'OMS lors de la conférence de presse sur COVID-19 11 mars 2020.

[9] Malik, S. (2020) Understanding the Impact of COVID-19 on Adolescents in India. International Journal of Indian Psychology, 8, 14-27.

[10] Varshney, M., Parel, J.T., Raizada, N. and Sarin, S.K. (2020) Initial Psychological Impact of COVID-19 and Its Correlates in Indian Community: An Online (FEEL-COVID) Survey. PLoS ONE, 15, e0233874.

https://doi.org/10.1371/journal.pone.0233874

[11] Wang, C., Pan, R., Wan, X., Tan, Y., Xu, L., Ho, C.S. and Ho, R.C. (2020) Immediate Psychological Responses and Associated Factors during the Initial Stage of the 2019 Coronavirus Disease (COVID-19) Epidemic among the General Population in China. International Journal of Environmental Research and Public Health, 17, 1729. https://doi.org/10.3390/ijerph17051729

[12] Zhang, Y. and Ma, Z.F. (2020) Impact of the COVID-19 Pandemic on Mental Health and Quality of Life among Local Residents in Liaoning Province, China: A Cross-Sectional Study. International Journal of Environmental Research and Public Health, 17, 2381. https://doi.org/10.3390/ijerph17072381

[13] YoungMinds (2020) Coronavirus: Impact on Young People with Mental Health Needs. https://youngminds.org.uk/media/3708/coronavirus-report march2020.pdf

[14] Rodríguez-Rey, R., Garrido-Hernansaiz, H. and Collado, S. (2020) Psychological Impact and Associated Factors during the Initial Stage of the Coronavirus (COVID-19) Pandemic among the General Population in Spain. Frontiers in Psychology, 11, 1540. https://doi.org/10.3389/fpsyg.2020.01540

[15] Uddin, M., Islam Md, N., Ahmed, O. and Lieberoth, A. (2020) COVID-19 Concern and Stress in Bangladesh: Perceived Social Support as a Predictor or Protector.

[16] González-Sanguino, C., Ausín, B., Castellanos, M.Á., Saiz, J., López-Gómez, A., 
Ugidos, C. and Muñoz, M. (2020) Mental Health Consequences during the Initial Stage of the 2020 Coronavirus Pandemic (COVID-19) in Spain. Brain, Behavior, and Immunity, 87, 172-176. https://doi.org/10.1016/j.bbi.2020.05.040

[17] Płomecka, M., Jawaid, A., Radziński, P., Gobbi, S., Neckels, R. and Baranczuk, Z. (2020) Mental Health Impact of COVID-19: A Global Study of Risk and Resilience Factors. https://doi.org/10.1101/2020.05.05.20092023

[18] Nair, S., Sagar, M., Sollers III, J., Consedine, N. and Broadbent, E. (2015) Do Slumped and Upright Postures Affect Stress Responses? A Randomized Trial. Health Psychology, 34, 632-641. https://doi.org/10.1037/hea0000146 